\title{
DIDACTIC TOOLS AND GEOGRAPHY TRAINING
}

\author{
DOI: http://dx.doi.org/10.18509/GBP.2019.77 \\ UDC: 37.02:91 \\ 37.018.8:91 \\ 37.091.33-028.22:91
}

\begin{abstract}
Maya Vasileva
Sofia University "St. Kliment Ohridski”, Faculty of Geology and Geography, Department "Regional development", Bulgaria
\end{abstract}

\begin{abstract}
Geography and geography education play the major role when we explore and present the interaction between nature and human society in space and in the different parts of the world. Consequently it assumes that we are handling with a great variety of information sources in the real training process. These sources are didactic tools which together with educational curriculum and methods are the main attribute and essence of geography teaching and learning. As didactic tools we define all objects which present the educational curriculum in verbal and/or visual way, and also in direct or indirect form. The different devices for reproduction of existing knowledge and those used for organization, control and management of training and educational process are considered also as tools used for didactic goals.

Didactic tools are important instrument helpful both for the teacher and the pupils. The didactic tools fulfill many didactic functions and definitely influence the quality and effectiveness of training process. These are our arguments why we have to pay attention to the topic in current research and demonstrate the immense importance of didactic tools in geography training. The main aim of the paper is to examine the right place of didactic tools in geography training and to present up-to-date didactic and methodical characteristic of them.
\end{abstract}

Keywords: didactic, geography didactic, geography training, didactical tools

\section{INTRODUCTION}

In the process of geography training a wide range of different tools is used encompassing a wide range of objects - the school buildings and furniture, school documentation, the various devices and apparatus that the teacher and the pupils work directly with. These are called training tools and are most commonly associated with all those objects that present in visual or verbal form the educational content (in direct or indirect form). The different devices for reproduction of existing knowledge and those used for organization, control and management of training and educational process are considered also as tools used for didactic goals.

The question of the training tools' system, its elements and functions is still open. This is a consequence of the different levels at which they are analyzed: theoretical level, level of content formation of the subject matter, level of studied material, level of school reality. The continuous change and the improvement of the training tools system is a consequence of the science and technology development, and also due to rapidly raising demands for more and better education and training.

The training tools perform various didactic functions and undoubtedly affect the quality and effectiveness of educational process. Therefore, the interest of the geography didactic 
in the subject is fully understandable. And in the current paper will be examined in brief the term "didactic tools" and presented their up-to-date didactic-methodological characteristic.

By their gist the didactic tools are a source of educational information and an instrument to aquire the educational content and to solve educational tasks [2]. They are "transmiters of subjectively selected and stored information" and connect the reality and their addressee/pupils [6]. The didactic tools' system is an aggregation of objects that are necessary and sufficient for conducting effectively the training process as a didactic cycle (during the geography lesson, in the lessons'system and outside it).The system of didactic tools is also part of geography education strategy for the secondary schools. Like any system, it incorporates relatively independent elements:

- the teacher's words (in various forms) - as the main source of information and a tool that cause its primary memorizing from pupils; as a tool for educative influence on students;

- the textbook and the whole training complex - as a source of information and a tool for its acquirement; as a tool for self-education, upbringing and self-directed behavior modification;

- tools for visualization - as a source of information or a tool for the full disclosure and learning of the educational content;

- technical devices - using them the information is transmitted in verbal and graphic form, as well as individualization of the training and machine control [1].

There are other approaches to classify the didactic tools. Some authors divide them in the following groups: natural resources, models, educational and technical tools, automated training systems, automated management systems. Taking into account, other scientists distinguish didactic tools as personal, classical and technical. Another recent classification, according to [3], arranges them in following groups:

- basic tools (textbook, atlas, wall map, white board, worksheets);

- typical geographic tools (globe, topographic map, satellite image, climatogram, GIS, compass, relief profile, etc.);

- common tools / tools used in everyday life (original objects, photos, cartoons, newspapers, tables, charts, thermometer, barometer, etc.)

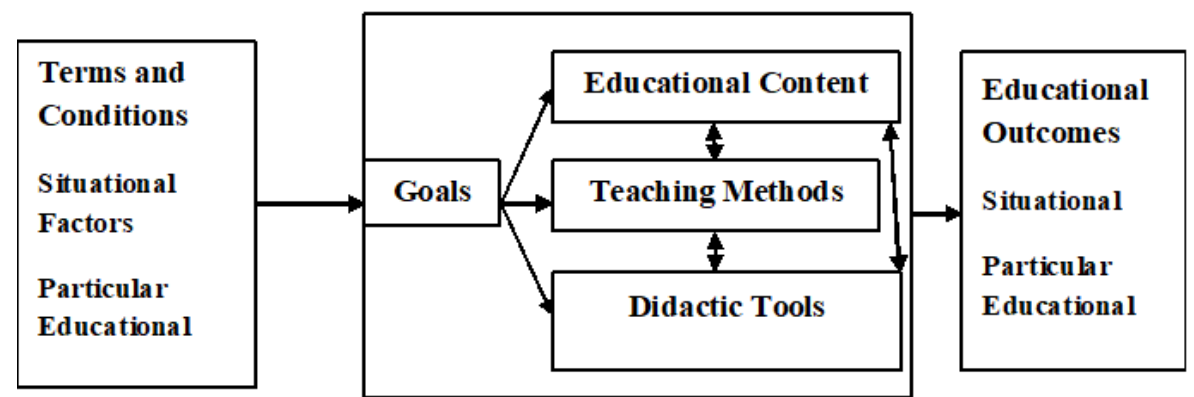

Figure 1. Place of didactic tools in geography education planning (by [7])

This classification is supplemented according to the oreintation of the didactic tools:

- illustrative and generating ideas (photo, original object, model, etc.);

- spatial-oriented (contour map, digital globe, road map, etc.);

- communicative (teacher's words, text in the textbook, newspaper commentary, interview, etc.); 
- quantitative and measuring (climatogram, GIS, GPS, compass, barometer, proximity sensors, etc.)

The didactic tools together with the educational content and methods are the key feature and attribute of geography teaching and learning. They are also an important starting point in planning the training process. (Fig.1)

Didactic tools perform many important functions in the training process. It is unthinkable the pupils to learn without using information sources in geography education. The wide diversity of didactic tools allows the achivment of a variety of learning objectives in the training process. The correlation between the functions of the didactic tools and the geography training goals is shown in the Table 1.

Table 1. Correlation between the didactic tools' functions and geography education goals [6]

\begin{tabular}{|l|l|}
\hline Functions of Didactic Tools & Goals of Geography Education \\
\hline Didactic tools transmit information. & $\begin{array}{l}\text { Cognitive goals } \\
- \text { Subject-thematic competence }\end{array}$ \\
\hline $\begin{array}{l}\text { Didactical tools develop methodological skills and } \\
\text { abilities. }\end{array}$ & $\begin{array}{l}\text { Instrumental goals } \\
- \text { Methodological competence }\end{array}$ \\
\hline Didactic tools "drive" the communication process. & $\begin{array}{l}\text { Social goals } \\
- \text { Social competence }\end{array}$ \\
\hline $\begin{array}{l}\text { Didactic tools stimulate the formation of ideas and } \\
\text { relations/attitudes. }\end{array}$ & $\begin{array}{l}\text { Affective / Emotional goals } \\
- \text { Moral competence }\end{array}$ \\
\hline Didactic tools are directed towards actions. & $\begin{array}{l}\text { "Action" goals } \\
\text { Competence for activity (Behavioral } \\
\text { competence) }\end{array}$ \\
\hline
\end{tabular}

In addition to the ones listed in the table, didactic tools perform other functions during the teaching and learning process which are used as strating point in lessons planning:

- To visualize and structure the studied objects (for example, using models and statistics);

- To emphasize (on the basic assumptions);

- To stimulate thinking (stimulating memory by visualizing);

- To inform and indirectly gain experience (e.g. movies can be used as it is unlikely during the lesson pupils to gather an immediate experience);

- To support the implemention of the training communication process (e.g. when the personal presence in the classroom is impossible - teaching through e-chat options, or when a co-operative work is done in a digital environment);

- To awake interest, to inspire motivation and mental activity (by presenting phenomena and objects through spectacular images or by emphasizing the relation between the educational content and the pupil's life);

- To construct a flexible and based on needs lesson structure (thus directing pupils attention, structuring the training process, dividing pupils into groups according to their knowledge, mitigating the routine work of recording and processing data, exercising and control of acquired knowledge by using worksheets, contour maps, making tests, etc.);

- Generate ideas and relations (to study a topic considering contradictory opinions);

- To create a new didactic tool (to practice the already learnt, to document and reflect the work results, e.g. own map, excursion movie, etc.) (adopted by [4], [7], [10]).

The effectiveness of using didactic tools in the training process is determined by their compliance with the objectives, educational content and lesson methods. The selection of 
didactic tools in the lesson should be targeted and be appropriate to pupils' needs. It is very important the didactic tools selection to be based on particular criteria and some of them are (adopted by [6]):

- Purposefulness - the didactic tools used in the lesson should address such educational content, questions and problems that will develop the pupils' geographical culture. In the planning of a study unit, the provided didactic tools should allow the optimal achievement of the respective educational goals and subgoals.

- Orientation to the educational content - Didactic tools used in education should match the current state of geography science and focus on such content that allows transfer to other examples in the surrounding space. Didactic tools should contain understandable/accessible content or be combined with additional information, explanations and definitions.

- Adequacy of the didactic tool and correspondence to the lesson structure-educational content may be structured in a different way, so the didactic tool should correspond with this structure. External features and distinctive aspects of geographic objects can be represented and described using pictures, drawings, maps, aerial photoes; and relationships, functional and causative links - using thematic maps, cartograms and diagrams.

- Perspective - didactic tools are "subjective". When selecting and presenting the curriculum, their compilers consciously or unconsciously express their subjective position. Subjectivity is also expressed when working with them in the training process.

- Compliance with the addressee - the selection and decision-making on the use of a didactic tool in a specific lesson stage must take into account the individual traits of the pupils, their interests, their learning and concentration abilities.

- Socialization function - besides cognitive and methodical competence, the didactic tools must also develop social competence. The important question is whether the didactic tool asks questions and seeks arguments, and suggests discussion and communication.

- Compliance with the principles of visualization and purposeful activity - the choice and place of the didactic tool in the training process must be in sync with the requirement "from visual to abstract" and "from simple to complex". As a information transmitter, the didactic tool should be relatively independent from the teacher, i.e. it must offer the most comprehensible content, clear and logical structure and visualization.

- Proper place when conducting lesson - didactic tools are generally appropriate for each stage of the lesson. However, in different stages they perform different functions, e.g. in the introductory stage (when it is necessary to wake up the pupils'interest) cartoons, riddles and jokes can be used.

- Organisational problems and prerequisites - the use of didactic tools requires time for preparation, financial costs, necessary working space, technical devices, etc.

Thus, the selection and use of didactic tools in the geography training must be justified. This requires both the didactic tools adaptation to the teaching and learning process and assessing the importance of the tool in particular case. First, the objectives to be achieved, using the didactic tool, should be defined in advance. And secondly, then the decisions can be made on the lesson methodological organization and the training. It is only then the choice of a didactic tool is justified and it focuses on answering the following questions: 
Table 2: Questions for selection of the didactic tools (adopted by [5], [4])

\begin{tabular}{|l|l|}
\hline Focus & Example \\
\hline Why? & $\begin{array}{l}\text { Does the didactic tool motivate the pupils? } \\
\text { Does it lead to a problematic situation? } \\
\text { Do we have a cognitive conflict? } \\
\text { Does it visualize the educational content? } \\
\text { Can pupils develop and exercise ways of working? } \\
\text { Which competencies can be developed? } \\
\text { Is it appropriate to consolidate, exercise or deepen the training outcomes? }\end{array}$ \\
\hline What? & $\begin{array}{l}\text { What educational content should be learnt? } \\
\text { Is the educational content adequately presented in didactic tool? } \\
\text { What is the perspective considering the set-up of the tool? }\end{array}$ \\
\hline How? & $\begin{array}{l}\text { Is the didactic tool appropriate for the social form of work used in the training } \\
\text { process? }\end{array}$ \\
\hline $\begin{array}{l}\text { Who is } \\
\text { studying? }\end{array}$ & $\begin{array}{l}\text { Is the tool appropriate for the pupil's age? } \\
\text { What previous knowledge for the educational content should pupils have? } \\
\text { What previous knowledge/skills for the didactic tool itself should pupils have? }\end{array}$ \\
Who is & $\begin{array}{l}\text { What competence does the teacher need to work with the didactic tool? (technical, } \\
\text { specialized) }\end{array}$ \\
\hline teaching? & $\begin{array}{l}\text { When is the proper time to use the tool (during the day, week or year)? } \\
\text { When should the teacher use the didactic tool according to the lesson stages? }\end{array}$ \\
\hline $\begin{array}{l}\text { How much } \\
\text { time? }\end{array}$ & \begin{tabular}{l} 
How long does it take to work with the tool? \\
\hline Where?
\end{tabular} \\
\hline How effective? & Where should the tool be used? (in the classroom, outside the school) \\
\hline
\end{tabular}

The answers to these questions are inherently related to the main task of the teacher - in the best way to integrate the chosen didactic tool in the real educational process aiming at developing a conscious, critical and responsible pupils'activity in the school and outside it. Or to paraphrase: The use of any didactic tool in the process of geography training cannot be self-aimed, thus it should always improve the cultivation of pupils' geographical culture.

The skill and competence for using didactic tools in geography education can be presented in the following way (Fig.2):

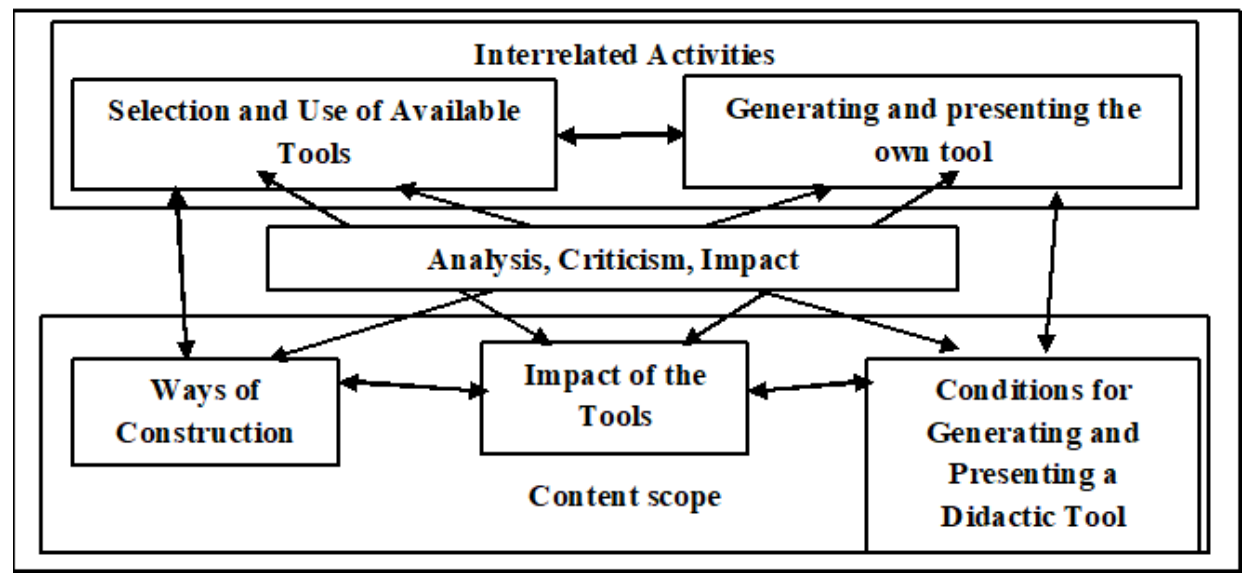

Figure 2. Model of competence for using didactical tools [9]

Consequently, the fulfillment of the following objectives and tasks leads to the development of competence for using the didactic tools in geography education: 
- Knowledge, analysis and selection of didactic tools - knowledge of the variety of didactic tools and their specifics with a view to choose the most appropriate to the educational content and the lesson's goals.

- Ways to create a didactic tool - forms and techniques for generating and presentation (graphics, text, film, animation, message, report).

- Creating and presenting your own didactic tool - a part of a project or excursion, examining and complying with economic, legal, political or other conditions.

- Use of didactic tools - practice and presention.

- Impact of didactic tools - impact on emotions, perceptions, behavior and value orientation. "Geography as a particularly informative subject plays an important role in this. In frequent work with texts, graphics, charts and maps, there is more and more opportunity to show how the same state of affairs can be presented in a different way. But it also could show how the chosen way of presentation emphasizes a certain conception, and even be distorted and manipulated" [8].

- Criticism of the didactic tools - critical survey of the educational content, its basic assumptions and the purposefulness of the didactic tools; to achieve an independent opinion as a result of working with various tools. (adopted by [9])

In general, the framework of competence teaching with didactic tools, especially in geography education, can be related to the following:

- Orientation in space - adequate use of maps, to conduct research on particular topic, sketching and creating simple maps.

- Acquiring knowledge - extracting geographic information from a didactic tool or in real space; describing the steps to acquire knowledge in geography.

- Assessment - evaluating the geographic information in the didactic tool according to different criteria.

\section{CONCLUSION}

Finnaly, all the above-mentioned allows us to summarize:

- Geography education uses a wide range of diverse didactic tools. They perform multiple functions and have a direct impact on the quality and efficiency of the teaching and learning process.

- Didactical tools together with the educational curriculum and methods play the key role and are the main attribute of geography teaching and learning. They are also an important starting point in the planning of the training process.

- The effectiveness of using the didactic tools in the training process is determined by their compliance with the objectives, educational content and lesson methods. The didactic tools selection in the lesson should be purposeful, appropriate to pupils' needs, and be a subject to the relevant selection criteria.

- The use of any didactic tool in the process of geography training cannot be self-aimed, it should always improve the cultivation of pupils' geographical culture.

\section{REFERENCES}

[1] Зорина, Л.Я. Средства обучения как система. Советская педагогика, 9, 1986

[2] Петров, П. Дидактика, С. УИ „Св. Климент Охридски“, 1992

[3] Fuchs, G. Zeitungsberichte im Erdkundenunterricht. Der Erdkundenunterricht 33. Stuttgart: Klett, 1980 
[4] Krauter, Y. Medien im Geographieunterricht nach lernförderlichen Kriterien auswählen. In: Reinfried, S. \& Haubrich, H. (Hrsg.). Geographie unterrichten lernen. Die Didaktik der Geographie. 1. Aufl. Berlin: Cornelsen, 2015, pp. 213-276

[5] Lehnert, H.-J., Köhler, K. Welche Medien werden im Biologieunterricht genutzt? In: Spörhase, U. (Hrsg.) Biologiedidaktik. Praxishandbuch für die Sekundarstufe I und II, Berlin: Cornelsen, 2012, pp. 152-174

[6] Rinschede, G. Geographiedidaktik. 3. Aufl. Paderborn u.a.: Ferdinand Schöningh, 2007

[7] Schaal, S. Die Arbeit mit Medien planen. In: Weitzel, H., Schaal, S. (Hrsg.). Biologie unterrichten: planen, durchführen, reflektieren, Berlin: Cornelsen, 2012, pp. 118-131

[8] Schneider, T. Medienerziehung, In: Böhn, D., Obermaier, G. (Hrsg.) Wörterbuch der Geographiedidaktik, Braunschweig: Westermann, 2013, pp. 187-188

[9] Tulodziecki, G., Herzig, B., Grafe, S. Lernen über Medien - die erzieherische Perspektive. In: Tulodziecki, G., Herzig, B., Grafe, S. (Hrsg.) Medienbildung in Schule und Unterricht. Grundlagen und Beispiele, Bad Heilbrunn: UTB, Klinkhardt, 2010, pp. 141-186

[10] von Martial, I. Medienfunktionen. In: von Martial, I., Ladenthin, V. Medien in Unterricht. Grundlagen und Praxis der Mediendidaktik, Batmannsweiler: Schneider, 2002, pp. 49-59 